\title{
Hydrodynamic model for three-phase internal- and external-loop airlift reactors
}

\author{
Carla Freitas $^{\mathrm{a}, *}$, Maria Fialová ${ }^{\mathrm{b}}$, Jindrich Zahradnik ${ }^{\mathrm{b}}$, José A. Teixeira ${ }^{\mathrm{a}}$ \\ ${ }^{\mathrm{a}}$ Centro de Engenharia Biológica - IBQF, Universidade do Minho, 4709 Braga, Portugal \\ bInstitute of Chemical Process Fundamentals, 16502 Prague 6, Suchdol, Czech Republic
}

\begin{abstract}
A mathematical model predicting the hydrodynamic behaviour of three-phase airlift reactors, working with low-density solids and with high solids loading, was developed. The model allows for the prediction of local gas holdup and liquid velocity in airlift bioreactors. Model was validated for an external-loop airlift reactor and an internal-loop airlift reactor with an enlarged degassing zone, being a good agreement obtained between calculated and experimental data. (C) 1999 Elsevier Science Ltd. All rights reserved.
\end{abstract}

Keywords: Three-phase reactor; Hydrodynamic model; Gas holdup; Liquid velocity

\section{Introduction}

Several models describing satisfactorily the hydrodynamics of two-phase airlift reactors have been developed (Chisti, Halard \& Moo-Young, 1988; Garcia-Calvo \& Letón, 1996; Kemblowski, Przywarski \& Diab, 1993). However, models describing the hydrodynamics of three-phase airlift reactors are limited, especially with low-density solids as the solid phase, which is the case in biotechnology processes.

Chisti et al. (1988) developed a two-phase model that was extended to a three-phase system by Livingston and Zhang (1993), to predict the liquid circulation velocity. A pseudo-homogeneous phase density for liquid-solid phase, considering different values for the riser and the downcomer, was used.

Lu, Hwang and Chang (1995) also developed a mathematical model for the prediction of the liquid velocity and of the gas holdup for three-phase airlift reactors, assuming that particles are well dispersed in the reactor. The solid phase and the liquid phase were regarded as a "pseudo-homogeneous mixture phase" and the threephase airlift reactor system was then reduced to a twophase system, containing the solid-liquid mixture phase and the gas phase.

\footnotetext{
* Corresponding author.
}

In this study, a model that allows for the estimation of gas holdup and liquid velocity in three-phase internalloop (ILR) and external-loop (ELR) airlift reactors, working with high solids loading, was developed. The concept of "pseudo-homogeneous mixture phase" was also employed.

\section{Theory}

In the present work some assumptions were made in the development of the mathematical model: The airlift reactor consists in four sections - the riser, the downcomer, the top and the bottom sections; the solid and the liquid phase were considered as a "pseudo-homogeneous mixture phase", with a constant density for the entire reactor; for the internal-loop reactor, the values of solids holdup used were the experimental ones and, for the external-loop reactor, it was considered that the distribution of solids is almost uniform, being the solids holdup equal, in every section of the reactor, to the solids loading.

\subsection{Riser gas holdup}

Riser gas holdup estimation was done using the equation proposed by Bando, Nishimura, Sota, Hattori, Sakai and Kuraishi (1990) for a three-phase system, as a modification of the Zuber and Findlay model (Clark 
\& Flemmer, 1985; Lu et al., 1995; Snape, Zahradník, Fialová \& Thomas, 1995).

$\varepsilon_{g r}=\frac{U_{g r}}{C\left(U_{g r}+U_{l r}+U_{s r}\right)+U_{b t}}$.

The riser superficial velocity of the solid particles relative to the reactor walls $\left(U_{s r}\right)$ is given by

$U_{s r}=\frac{\varepsilon_{s r} U_{l r}}{\left(1-\varepsilon_{g r}-\varepsilon_{s r}\right)}-\varepsilon_{s r} U_{s t}$.

The solids settling velocity $U_{s t}$ was calculated using a correlation for spherical particles and Reynolds number between 1000 and 350000 (Perry \& Green, 1984):

$U_{s t}=1.73 \sqrt{g D_{p}\left(\rho_{p}-\rho\right) / \rho}$.

Replacing $U_{s r}$ (Eq. (2)) into Eq. (1), the riser gas holdup is given by

$\varepsilon_{g r}=$

$$
\frac{U_{g r}}{C\left[U_{g r}+U_{l r}\left(1+\varepsilon_{s r} /\left(1-\varepsilon_{g r}-\varepsilon_{s r}\right)\right)-\varepsilon_{s r} U_{s t}\right]+U_{b t}} .
$$

In the present study, Eq. (4) was used to fit the experimental values of riser gas holdup, optimising the values of the distribution factor $C$ and the terminal rise velocity of a single bubble $U_{b t}$.

\subsection{Downcomer gas holdup}

Several authors (Chisti, 1989) found linear relationships between riser and downcomer gas holdup. Therefore, with the value of riser gas holdup given by Eq. (4), downcomer gas holdup for the internal-loop reactor was calculated using the equation:

$\varepsilon_{g d}=a \varepsilon_{g r}+b$.

Calculation of parameters $a$ and $b$ was included in the optimisation procedure.

For the external-loop reactor, the downcomer gas holdup is negligible.

\subsection{Riser superficial liquid velocity}

An energy balance was used for the prediction of the riser superficial liquid velocity. The basis of the balance is to equate the head differential that causes liquid circulation between the riser and the downcomer $\left(P_{h}\right)$ and the head losses due to friction $\left(-\Delta P_{\text {loss }}\right)$.

$P_{h}$ is given by

$P_{h}=\left[\left(\rho_{h} \varepsilon_{h d}+\rho_{g} \varepsilon_{g d}\right)-\left(\rho_{h} \varepsilon_{h r}+\rho_{g} \varepsilon_{g r}\right)\right] g H_{r, d}$,

where $\rho_{h}$ is the pseudo-homogeneous-phase density.
Since $\rho_{h}$ is much larger than $\rho_{g}$ and as the pseudohomogeneous-phase density can be expressed by

$\varepsilon_{h}=1-\varepsilon_{g}$.

Eq. (6) becomes in the form:

$P_{h}=\left(\varepsilon_{g r}-\varepsilon_{g d}\right) \rho_{h} g H_{r, d}$.

The total frictional loss in the airlift reactor is

$-\Delta P_{\text {loss }}=\sum\left(-\Delta P_{f}\right)_{i}$.

$\left(-\Delta P_{f}\right)_{i}$ is the frictional loss in each section $i$ of the reactor and can be obtained by (Brodkey \& Hershey, 1988):

$\left(-\Delta P_{f}\right)_{i}=\frac{1}{2} \rho_{h} k_{f i} V_{l i}^{2}$,

where $k_{f i}$ is the friction coefficient in section $i$ of the reactor.

\subsubsection{Friction coefficients}

Standard "one-phase flow" equations were used to calculate the friction coefficients in specific parts of each airlift reactor:

- Internal-loop airlift reactor: In the reactor tubes (riser and downcomer) and bottom of the reactor; the friction coefficient in the top is negligible.

- External-loop airlift reactor: In the reactor tubes (riser, downcomer, top and bottom sections), in fittings and diameter changes.

Reactor tubes. The friction loss coefficient in lines of circular cross section was calculated according to (Brodkey \& Hershey, 1988):

$k_{f i}=4 f_{i} \frac{H_{i}}{D_{i}}$,

where $f_{i}$ is the friction factor of the pseudo-homogeneous mixture in section $i$.

The Blasius equation (Perry \& Green, 1984), for onephase and turbulent flow, was applied to a three-phase system, determining $f$ for the pseudo-homogeneous mixture

$f=0.0791 R e_{h}^{-0.25}$,

where Reynolds number of the pseudo-homogeneous phase for section $i\left(R e_{h i}\right)$ is given by

$R e_{h i}=\frac{\rho_{h i} V_{l i} D_{i}}{\mu_{h i}}$. 
A correction factor $\alpha$, proposed by Garcia-Calvo and Letón (1996) for systems where two-phase flow is present, was also introduced. So, considering that $\mu_{h}$ and $\rho_{h}$ are constant for the entire reactor, Eq. (11) becomes

$k_{f i}=\frac{4^{*} \alpha^{*} 0.0791 H_{i} \mu_{h}^{0.25}}{\rho_{h}^{0.25} D_{i}^{1.25} V_{l i}^{0.25}}$.

As $\rho_{h}, \mu_{h}$ and $\alpha$ depend on the solids loading, a parameter $\beta$ was considered

$\beta=\alpha^{*} 4^{*} 0.0791 * \mu_{h}^{0.25} \rho_{h}^{-0.25}$.

Bottom and top friction coefficient for the internal-loop reactor. Since $k_{f b} \gg k_{f t}$ for internal loop airlift reactors, $k_{f t}$ is negligible and $k_{f b}$ was calculated by (Chisti et al., 1988):

$k_{f b}=11.4\left(\frac{A_{d}}{A_{b}}\right)^{0.79}$

valid for an $A_{d} / A_{b}$ range of $0.2-1.8 . A_{b}$ is the free area below the draught tube.

Fittings. In the external-loop airlift reactor there are two elbows ("screwed long radius $90^{\circ}$ ell") - connecting the top tube to the downcomer $-K_{f t, d}-$ and the downcomer to the bottom tube $-K_{f d, b}$, which depend on the nominal size, a "sharp edged entrance" from the riser into the top section $\left(K_{f r, t}\right)$ and a "sharp edged exit" from the bottom section into the riser $\left(K_{f b, r}\right)$. From Brodkey and Hershey (1988), $K_{f t, d}=0.25, K_{f d, b}=0.40$, $K_{f r, t}=0.50, K_{f b, r}=1.0$.

Diameter change. There are two types of diameter changes in the external-loop reactor, a "gradual contraction" in the top section $\left(K_{f g c}\right)$ and a "sudden contraction" in the downcomer $\left(K_{f s c}\right)$. From Brodkey and Hershey (1988):

$K_{f g c}=0.04$,

$k_{f s c}=0.42\left(1-\frac{d_{2}^{2}}{d_{1}^{2}}\right), \frac{d_{2}}{d_{1}} \leqslant 0.76$.

At steady state (Lu et al., 1995):

$P_{h}=-\Delta P_{\text {loss }}$.

Combining this equation with Eqs. (8)-(10) and (14) and knowing that

$V_{l i}=\frac{U_{l i}}{1-\varepsilon_{g i}-\varepsilon_{s i}}$,

and that for a section $i$

$A_{i} U_{l i}=A_{r} U_{l r}$

the final equations for the riser superficial velocity become
Internal-loop Airlift Reactor:

$$
\begin{aligned}
2 g H\left(\varepsilon_{g r}-\varepsilon_{g d}\right)= & \left(\frac{A_{r}}{A_{d}}\right)^{2} \frac{k_{f b}}{\left(1-\varepsilon_{g d}-\varepsilon_{s d}\right)^{2}} U_{l r}^{2} \\
& +\left[\frac{D_{r}^{-1.25}}{\left(1-\varepsilon_{g r}-\varepsilon_{s r}\right)^{1.75}}+\left(\frac{A_{r}}{A_{d}}\right)^{1.75}\right. \\
& \left.\times \frac{\left(D_{c}-D_{r}\right)^{-1.25}}{\left(1-\varepsilon_{g d}-\varepsilon_{s d}\right)^{1.75}}\right] H \beta U_{l r}^{1.75} .
\end{aligned}
$$

External-loop airlift reactor:

$$
\begin{aligned}
2 g H \varepsilon_{g r}= & {\left[\frac{\left(H_{r}+H_{t}\right) D_{r}^{-1.25}}{\left(1-\varepsilon_{g r}-\varepsilon_{s}\right)^{1.75}}+\left(\frac{A_{r}}{A_{d}}\right)^{1.75} \frac{\left(H_{d}+H_{b}\right) D_{d}^{-1.25}}{\left(1-\varepsilon_{s}\right)^{1.75}}\right] } \\
& \times \beta U_{l r}^{1.75}+k_{f r, t} \frac{U_{l r}^{2}}{\left(1-\varepsilon_{g r}-\varepsilon_{s}\right)^{2}} \\
& +\left[\left(\frac{A_{r}}{A_{t, d}}\right)^{2}\left(k_{f t, d}+k_{f g c}\right)+\left(\frac{A_{r}}{A_{d}}\right)^{2}\left(k_{f s c}\right.\right. \\
& \left.\left.+k_{f d, b}+k_{f b, r}\right)\right] \frac{U_{l r}^{2}}{\left(1-\varepsilon_{s}\right)^{2}} .
\end{aligned}
$$

\section{Experimental}

The internal-loop airlift reactor (ILR) used is of the concentric-tube type, with an enlarged degassing zone, as described in Freitas and Teixeira (1997). The diameters of the downcomer and the riser are 0.142 and $0.062 \mathrm{~m}$, respectively. The height of the draught tube is $1.190 \mathrm{~m}$ and its bottom edge is $0.086 \mathrm{~m}$ above the bottom of the reactor.

The glass wall external-loop airlift reactor (ELR) used, similar to the reactor shown in Snape et al. (1995), has a downcomer and a riser diameter of 0.05 and $0.158 \mathrm{~m}$, respectively, with $2.07 \mathrm{~m}$ height. The top section has a height and a diameter of 0.36 and $0.158 \mathrm{~m}$, respectively, with a contraction that connects to a bend of $0.107 \mathrm{~m}$ of diameter. At the end of this, there is another contraction to reduce the diameter of the bend to the downcomer diameter. This has the same diameter as the bottom section and the bend that connects them. Both reactors have a working volume of 601 .

Air was used as the gas phase and injected through perforated plates with $1 \mathrm{~mm}$ holes. The airflow rate was varied in a way that the riser superficial gas velocities studied were between 0.01 and $0.50 \mathrm{~m} / \mathrm{s}$, for the ILR, and between 0.03 and $0.17 \mathrm{~m} / \mathrm{s}$, for the ELR.

The liquid-phase used was water, in the case of the ELR, and an aqueous solution of $10 \mathrm{~g}$ ethanol/1, in the ILR.

Ca-alginate beads with a density of $1023 \pm 1 \mathrm{~kg} / \mathrm{m}^{3}$ and a diameter of, approximately, $2 \mathrm{~mm}$ were applied as 
solid phase, for different solids loading $(0,10,20$ and $30 \%$ $\mathrm{v} / \mathrm{v})$.

Riser gas holdup was determined with a manometer, in the ELR, and with pressure transducers, in the ILR (Freitas et al., 1997).

The measurements of the liquid velocity were done, in the ELR, using a conductivity pulse technique (Snape et al., 1995) and, for the ILR, with the $\mathrm{pH}$ pulse technique (Freitas et al., 1997).

The optimisation of the parameters $C, U_{b t}, a, b$ and $\beta$ (Eqs. (4), (5), (21) and (22)), allowing for the prediction of values of riser and downcomer (for the ILR) gas holdup and the riser superficial liquid velocity, was done using a developed computer software.

\section{Results and discussion}

The results of simulations of gas holdup and riser liquid velocity, for the internal- and the external-loop reactors, carried out for each solids loading, are presented in Figs. 1 and 2. As can be seen, there is, in general, a good agreement between the predicted and the measured values of gas holdup in the riser and in the downcomer. However, for the ILR, when working with $30 \%$ of solids and low airflow rates, values predicted for the riser gas holdup and riser liquid velocity are significantly different from the measured ones. For this reactor, the circulation becomes very difficult when working with high solids loading and low airflow rates. In these conditions, due to the existence of a zone at the bottom of the reactor where a high concentration of solids occurs, the assumption of the existence of two-phases is no longer valid. For the ELR, the deviation of the predicted values from the experimental ones is not significant. This is
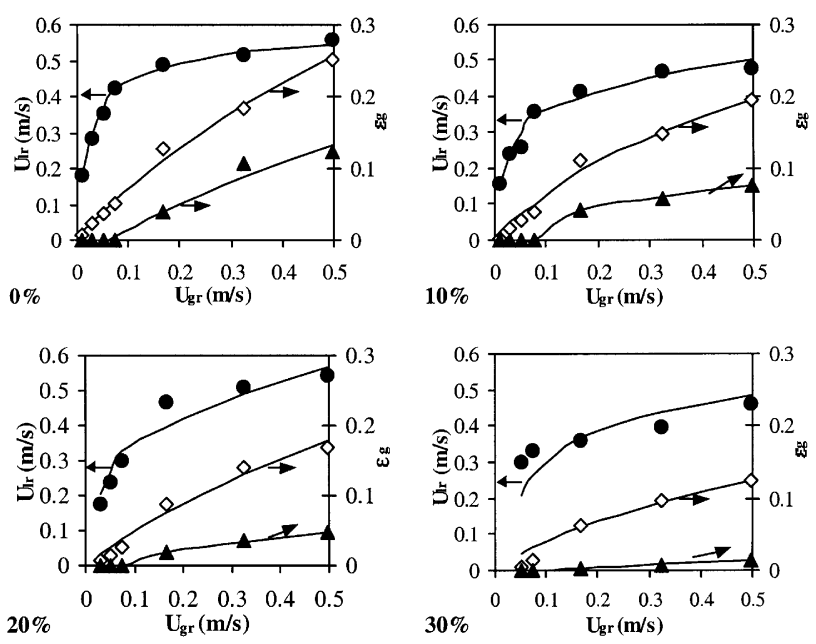

Fig. 1. Riser superficial liquid velocity $(\bullet)$, riser gas holdup $(\diamond)$ and downcomer gas holdup $(\boldsymbol{\Delta})$ vs. riser superficial gas velocity (— predicted values), for different solids loading (ILR).
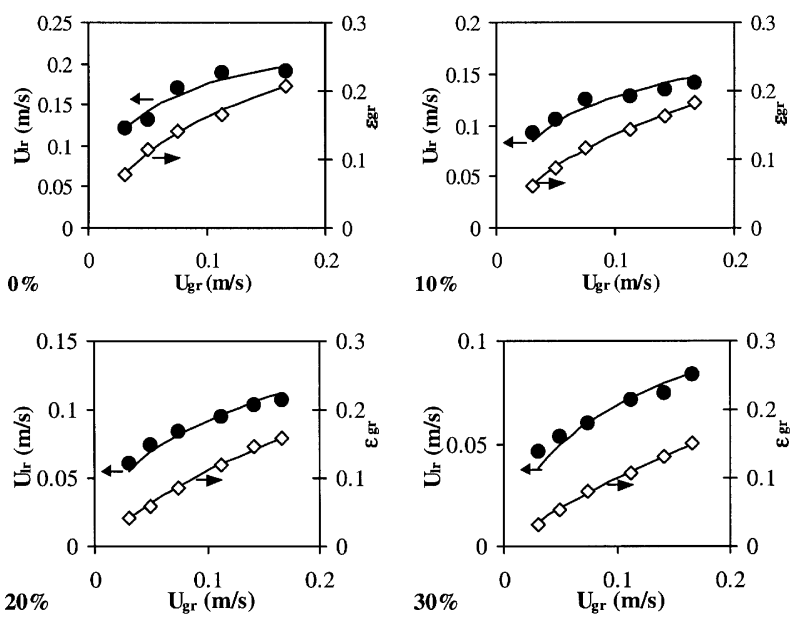

Fig. 2. Riser superficial liquid velocity $(\bullet)$ and riser gas holdup $(\diamond)$ vs. riser superficial gas velocity (— predicted values), for different solids loading (ELR).

because the riser in the ELR is very large, what allows for a good circulation of the fluid, even if there is a high concentration of solids.

The distribution factor $C$ is an index of the flow pattern and it is equal to 1 when the flow distribution is radially uniform. However, the fact that $C$ is near unity in magnitude should not be misinterpreted as indicating that plug flow prevails. The magnitude of the distribution parameter is due to the uniformity of the void distributions rather than the character of the phase velocity profile (Young, Carbonell \& Ollis, 1991). According to Zuber and Findlay (Shah \& Deckwer, 1983), if the holdup and velocity drop linearly from the centre of the tube to the wall, the value of the parameter $C$ varies from 1.5 to 1 , for fully established profiles. It can be seen from the values of $C$ (Table 1) that, after an increase (very small for the ELR) till $10 \%$ of solids, it decreases with the increase of solids loading. With the introduction of solids (till 10\%) the flux is perturbed but, when more solids are added, the flux becomes more uniform and values of $C$ approach 1. Circulation restrictions in the ILR may explain the non-uniformity of the flux, for $30 \%$ of solids.

Values of the terminal velocity of a single bubble $\left(U_{b t}\right)$ increase, in general, with the increase of solids loading, being higher for the ILR. Such results can be ascribed to the character of the bubble bed in the riser. In the "drift-flux model" (Young et al., 1991), $U_{b t}$ is the terminal velocity of a single bubble, assuming that bubbles do not interact, that is, each bubble moves independently and is not affected by the presence of other bubbles. For the ILR, values of the parameter $U_{b t}$ show that, even for the low solids loading, for which the fits are very good, values are high, comparing with values obtained by other authors (Bando et al., 1990; Lu et al., 1995). Even for 0\% 
Table 1

Values of the optimised parameters $C, U_{b t}, \beta, a$ and $b$

\begin{tabular}{|c|c|c|c|c|c|c|c|c|}
\hline $\begin{array}{l}\text { Solids loading } \\
(\%)\end{array}$ & \multicolumn{5}{|c|}{ Internal-loop reactor } & \multicolumn{3}{|c|}{ External-loop reactor } \\
\hline 10 & 1.74 & 0.68 & 0.11 & 0.354 & 0.0068 & 2.14 & 0.22 & 0.010 \\
\hline 20 & 1.13 & 1.38 & 0.076 & 0.280 & -0.0023 & 1.53 & 0.58 & 0.016 \\
\hline 30 & 2.21 & 1.22 & 0.069 & 0.184 & -0.0083 & 1.20 & 0.77 & 0.024 \\
\hline
\end{tabular}

of solids, the $U_{b t}$ value is outside the range of $0.2-0.4 \mathrm{~m} / \mathrm{s}$ presented in literature for two-phase systems. This may be explained by the small riser cross-sectional area, causing the existence of a swarm of bubbles rising with very high velocities. For the ELR, although the $U_{b t}$ increases, it only presents values higher than $0.4 \mathrm{~m} / \mathrm{s}$ for the higher solids loading (20 and $30 \%$ ). In these cases, the spaces between the solids are small what leads to an increase of the interaction between the bubbles, increasing coalescence with the consequent increase of bubbles diameter. The larger the size of the bubbles the higher the values of the riser velocity.

Also from Table 1, it can be seen that the parameter $\beta$ responds in different ways to the increase of solids loading, for the two types of reactors. For the internalloop airlift reactor, $\beta$ decreases for solids loading higher than $10 \%$. Since $\beta$ is directly proportional to the pseudo-homogeneous phase viscosity and to the correction factor $\alpha$ and inversely proportional to density (Eq. (15)), the decrease of $\beta$ indicates that, for these high solids concentration, the density of the "pseudo-homogeneous-phase" is the main factor responsible for the high losses. On the contrary, $\beta$ increases with solids loading in the ELR what could be the result of an increase of the correction factor. As the geometries of the two reactors are very distinct, specially in what concerns the ratio between the riser and the downcomer diameters (for the ILR, $D_{r} / D_{d}<1$ and for the ELR, $D_{r} / D_{d}>1$ ), changes on viscosity, density and friction with the increase of solids loading will have different consequences on the hydrodynamics of both reactors. Furthermore, if, as an approximation, the viscosity and density of water $(0.001 \mathrm{~N}$ s and $1000 \mathrm{~kg} / \mathrm{m}^{3}$ ) are considered to obtain the values of $\beta$, the correction factor $\alpha$ should have a value of about 10 , for the ILR, and of about 1, for the ELR. Garcia-Calvo and Letón (1996) proposed for a two-phase flow system a value of 2 . This means that the third phase has a higher influence on the hydrodynamics of the internal-loop than on the external-loop airlift reactor, deriving from the differences on their geometry.

Parameter $a$ (Eq. (5)), for the ILR, decreases with the increase of solids loading since the larger bubbles formed rise faster and enter in the downcomer in lower amounts.

\section{Conclusions}

From the results presented, it can be concluded that the model predicts the experimental values found for both types of airlift reactors with high accuracy (with an error of $\pm 10 \%$ ), despite the high number of simplifying assumptions introduced for calculations. Only for the internal-loop reactor some difficulties on estimation of the values for $30 \%$ of solids and low airflow rates were found.

For both reactors, for the estimated parameters, a similar effect of the solids loading on hydrodynamics was found. The distribution parameter presents some oscillations showing that, depending on the amount of solids, the solid-phase affects the flux in different ways. The terminal velocity of a single bubble increases with the increase of solids loading, as a consequence of the increase of coalescence deriving from the increase of the interaction between the bubbles. The parameter $\beta$ exhibits different trends for the two reactors, resulting from their distinct geometries.

\section{Notation}

A cross-sectional area, $\mathrm{m}^{2}$

$a, b \quad$ parameters

$A_{b} \quad$ free area below the draught tube, $\mathrm{m}^{2}$

$C$ distribution parameter

$d_{1}, d_{2} \quad$ diameter of the tubes in a sudden contraction, $\mathrm{m}$

$D_{p} \quad$ solid particle diameter, $\mathrm{m}$

D diameter, $\mathrm{m}$

$f$

$g$

$H$

$k_{f}$

$P_{h}$

Re

$U$

$U_{b t}$ friction factor of the pseudo-homogeneous mixture gravitational acceleration, $\mathrm{m} / \mathrm{s}^{2}$ length, $\mathrm{m}$ friction loss coefficient hydrostatic pressure difference between riser and downcomer, $\mathrm{Pa}$

Reynolds number superficial velocity, $\mathrm{m} / \mathrm{s}$ terminal velocity of a single bubble, $\mathrm{m} / \mathrm{s}$ 
$U_{s t} \quad$ solids settling velocity, $\mathrm{m} / \mathrm{s}$

$V \quad$ linear velocity, $\mathrm{m} / \mathrm{s}$

\section{Greek letters}

$\alpha \quad$ correction factor

$\beta \quad$ parameter

$\left(-\Delta P_{f}\right) \quad$ friction loss, $\mathrm{Pa}$

$-\Delta P_{\text {loss }}$ total frictional loss in the reactor, $\mathrm{Pa}$

$\varepsilon \quad$ holdup

$\mu \quad$ viscosity, $\mathrm{N}$ s

$\rho \quad$ density, $\mathrm{kg} / \mathrm{m}^{3}$

\section{Subscripts}

$\begin{array}{ll}b & \text { bottom section } \\ d & \text { downcomer } \\ g & \text { gas } \\ g c & \text { gradual contraction } \\ h & \text { homogeneous-phase } \\ i & \text { section } \\ l & \text { liquid } \\ p & \text { solid particle } \\ r & \text { riser } \\ s & \text { solid } \\ s c & \text { sudden contraction } \\ t & \text { top section }\end{array}$

\section{Acknowledgements}

This work was supported by FCT (Fundação para a Ciência e a Tecnologia), under project PRAXIS/2/2.1/ $\mathrm{BIO} / 1061 / 95$ and grant GGP XXI/BD/2937/96 awarded to Carla Maria Duarte de Freitas and by EC, under INCOCOPERNICUS contract N ${ }^{\circ}$ ERB IC15-CT98-0904.

\section{References}

Bando, Y., Nishimura, M., Sota, H., Hattori, M., Sakai, N., \& Kuraishi, M. (1990). Flow characteristics of three-phase fluidized bed with draft tube - effect of outer column diameter and determination of gas-liquid interfacial area. Journal of Chemical Engineering in Japan, 23, 587-592.

Brodkey, R. S., \& Hershey, H. C. (1988). Transport Phenomena - a unified approach (pp. 400-442). New York, USA: McGraw-Hill.

Chisti, M. Y., Halard, B., \& Moo-Young, M. (1988). Liquid circulation in airlift reactors. Chemical Engineering Science, 43, 451-457.

Chisti, Y. (1989). In Airlift reactors (p. 71). London: Elsevier.

Clark, N. N., \& Flemmer, R. L. (1985). Prediction the holdup in twophase bubble upflow and downflow using the Zuber and Findlay drift-flux model. The American Institute of Chemical Engineers Journal, 31, 500-503.

Freitas, C., \& Teixeira, J. A. (1997). Hydrodynamic studies in an airlift reactor with an enlarged degassing zone. Bioprocess Engineering, 18, 267-279.

Garcia-Calvo, E., \& Letón, P. (1996). Prediction of gas hold-up and liquid velocity in airlift reactors using two-phase flow friction coefficients. Journal of Chemical Technology and Biotechnology., 67, 388-396.

Kemblowski, Z., Przywarski, J., \& Diab, A. (1993). An average gas hold-up and liquid circulation velocity in airlift reactors with external loop. Chemical Engineering Science, 48, 4023-4035.

Livingston, A. G., \& Zhang, S. F. (1993). Hydrodynamic behaviour of three-phase (gas-liquid-solid) airlift reactors. Chemical Engineering Science, 48, 1641-1654.

Lu, W.-J., Hwang, S.-J., \& Chang, C.-M. (1995). Liquid velocity and gas holdup in three-phase internal loop airlift reactors with low-density particles. Chemical Engineering Science, 50, 1301-1310.

Perry, R. H., Green, D. W., (1984). Perry's chemical engineers handbook, (6th ed.) (p. 564). New York, USA: McGraw Hill.

Shah, Y. T., \& Deckwer, W.-D. (1983). Hydrodynamics of bubble columns. In Handbook of fluids in motion (p. 592). Ann Anbor, MI: Ann Arbor Science.

Snape, J. B., Zahradník, J., Fialová, M., \& Thomas, N. H. (1995) Chemical Engineering Science, 50, 3175-3186.

Young, M. A., Carbonell, R. G., \& Ollis, D. F. (1991). Airlift bioreactors: Analysis of local two-phase hydrodynamics. The American Institute of Chemical Engineers Journal, 37, 403-428. 